Studia Kinanthropologica, XVIII, 2017, (2), 109-114

The Scientific Journal for Kinanthropology

POROVNÁNÍ VNITŘNÍ ODEZVY ORGANISMU NA ZATÍŽENÍ V UTKÁNÍ BĚHEM SPECIFICKÉHO BASKETBALOVÉHO ÚNAVOVÉHO PROTOKOLU

\title{
COMPARISON OF INTERNAL WORKLOAD RESPONSE DURING A MATCH AND BASKETBALL-SPECIFIC FATIGUE PROTOCOL
}

\author{
K. Hůlka, ${ }^{1}$ M. Botek, ${ }^{2}$ M. Lehnert,${ }^{1}$ J. Bělka, ${ }^{1}$ M. Opavský, ${ }^{1}$ T. \& T. Vilímová ${ }^{3}$ \\ ${ }^{1}$ Univerzita Palackého v Olomouci, Fakulta tělesné kultury, Katedra sportu \\ ${ }^{2}$ Univerzita Palackého v Olomouci, Fakulta tělesné kultury, Katedra př́rodních věd v Kinantropologii \\ ${ }^{3}$ Univerzita Palackého v Olomouci, Fakulta tělesné kultury, Katedra fyzioterapie
}

\begin{abstract}
The goal of the study was to compare internal workload response during a match and basketballspecific fatigue protocol. The study involved a total of 29 male basketball players (age $17.4 \pm 1.6$ years; body height $=184.7 \pm 8.2 \mathrm{~cm}$ and weight $=75.7 \pm 15.6 \mathrm{~kg}$ ) of U17 and U19 categories. Heart rate, blood lactate concentration, and Borg scale were used. We found out moderately strong correlation between heart rate during a match and basketball-specific fatigue protocol. Similar results were detected in blood lactate concentration.
\end{abstract}

Keywords: heart rate; specificity; blood lactate concentration

\section{SOUHRN}

Cílem studie bylo ověření validity měření specifickým basketbalovým únavovým protokolem $\left(\mathrm{SBFP}_{28}\right)$ pomocí porovnání vnitřní odezvy organismu na zatížení během $\mathrm{SBFP}_{28}$ a utkáním. Výzkumu se zúčastnilo celkem 29 hráčů basketbalu kategorií U17 a U19 ve věku 17,1 $\pm 1,6$ let s hmotností 75,7 $\pm 15,6 \mathrm{~kg}$ a výškou $184,7 \pm 8,2 \mathrm{~cm}$. Pro zjištění vnitřní odezvy organismu bylo použito monitorování srdeční frekvence, koncentrace krevního laktátu z kapilární krve a Borgova škála subjektivního vnímání zatížení. Porovnáním výsledků monitorování srdeční frekvence během přátelského utkání a testu $\mathrm{SBFP}_{28}$ jsme zjistili středně silnou statisticky významnou korelaci. Podobně tomu bylo i u sledování pozátěžové hladiny laktátu v krvi u obou sledovaných aktivit.

Klíčová slova: srdeční frekvence; specifičnost; koncentrace krevního laktátu

\section{Úvod}

Basketbal patří mezi sporty, jehož výkon je intermitentního charakteru (Hůlka, Cuberek, \& Bělka, 2013). Znamená to, že v sobě kombinuje činnosti maximální intenzity s činnostmi intenzity střední a nízké (Apostolidis, Nassis, Bolatoglou, \& Geladas, 2004). Činnosti, jako např́iklad starty na míč, běh pozpátku, starty, změny směru, výskoky, pohyb v obranném postoji a podobně, jsou při hře prováděny při vysoké až maximalní intenzitě a jsou proloženy (kombinovány) s pohyby o nižší intenzitě (Narazaki, Berg, Stergiou, \& Chen, 2009). Činnosti nízké intenzity pak slouží k zotavení organismu před další činností (Krustrup, Mohr, \& Bangsbo, 2002). Fakt intermitence zatížení zcela mění, v porovnání se sporty cyklického charakteru, metabolické požadavky organismu na výkon hráče v utkání (Ben Abdelkrim, Castagna, El Fazaa, Tabka \& El Ati, 2009). Proto je nezbytná analýza zatížení hráčů v utkání, a to jak vnějšího zatížení, tak i vnitřní odezvy organismu na toto zatížení (Mathew \& Delextrat, 2009). Znalost metabolických potřeb organismu během utkání může sloužit jako podklad pro plánování specifického tréninku, který může vést $\mathrm{k}$ růstu herního výkonu hráčů $\mathrm{v}$ basketbale (McKeag, 2003). 
Hráči basketbalu během utkání překonají vzdálenost 4500 m až 6300 m (Erčulj et al, 2008; Hůlka, Cuberek \& Bělka, 2013; Narazaki et al., 2009), vykonají 800 až 1050 změn směru, zrychlení, či zpomalení (Ben Abdelkrim, El Fazaa \& El Ati, 2007; Klusemann et al., 2013; McInnes et al., 1995) a 40 až 50 výskoků (Ben Abdelkrim et al., 2007). Taylor (2004) zjistil, že během utkání každý hráč absolvuje $105 \pm 51$ činností maximální intenzitou $\left(>5,10 \mathrm{~m} \cdot \mathrm{s}^{-1}\right)$. McInnes et al. (1995) zjistili, že hráči stráví $35 \%$ času utkání chůzí ( $\mathrm{v}$ tempu do $1 \mathrm{~m} \cdot \mathrm{s}^{-1}$ ) nebo nečinností a pouze přibližně $15 \%$ činnostmi vysokou až maximální intenzitou. Průměrná srdeční frekvence se pohybuje v rozmezí od 87 do $91 \%$ maximální srdeční frekvence (Abdelkrim et al., 2006; McInnes et al., 1995; Montgomery, Pyne, \& Minanhan, 2010; Ziv \& Lindor, 2009). Hladina laktátu, jakožto ukazatel anaerobního metabolismu na tvorbě ATP se v utkání pohybuje v rozmezí od 4,2 $\mathrm{mmol} \cdot \mathrm{L}^{-1}$ až po $5,75 \mathrm{mmol} \cdot \mathrm{L}^{-1}$ (Ben Abdelkrim et al., 2010; Mathews \& Delextrat, 2009; Narazaki, 2007).

Pro integraci potřeb specifičnosti zatížení a kondičního testování hráčů basketbalu se pozornost upíná na metabolické odezvy organismu, které velmi úzce korespondují s těmi, během výkonu hráčů v utkání (Gamble, 2007). Obzvláště pak u kondičních testových baterií či profilů se začíná dbát na relevantnost, resp. validitu testovaných kondičních předpokladů (Gamble, 2006; National Coaching Foundation, 1995). Každý nově konstruovaný kondiční motorický test, jehož úkolem je bud' poukázat na kondiční způsobilost podávat optimální výkon v utkání, anebo simulovat únavu, která je co nejvíce podobná té po utkání. Je proto nutné co nejlépe ověřit vlastnosti těchto protokolů.

K potřebám výzkumu velikosti a typu únavy a jejího vliv na aktuální zdravotní stav hráčů po utkání vznikají únavové protokoly, jejichž cílem je co nejvěrněji kopírovat zatížení hráčů během utkání (Scanlan, Dascombe \& Reaburn, 2012). Každý nově konstruovaný kondiční test, jehož úkolem je bud' poukázat na kondiční způsobilost podávat optimální výkon v utkání, anebo simulovat únavu, která je co nejvíce podobná té po utkání. Je proto nutné co nejlépe ověřit vlastnosti těchto protokolů (Hůlka, Bělka, Cuberek, \& Schneider, 2014). Pro jejich využitelnost v praxi se po zkonstruování protokolu ověřuje reliabilita a validita protokolu. Cílem studie bylo ověření validity měření specifickým basketbalovým únavovým protokolem $\mathrm{SBFP}_{28}$ pomocí porovnání vnitřní odezvy organismu na zatížení během $\mathrm{SBFP}_{28}$ a utkáním. $\mathrm{SBFP}_{28}$ ukazuje vysokou reliabilitu, kdy inter-individuální variabilita se uváděna 2,64 až 5,52 \% a intra-individuální stabilita pak 2,69 - 7,61 \% (Hůlka, Lehnert \& Bělka, 2017).

\section{Metody}

\section{Participanti}

Výzkumu se zúčastnilo celkem 29 hráčů basketbalu kategorií U17 a U19 ve věku 17,44 $\pm 1,52$ let s hmotností $75,74 \pm 15,60 \mathrm{~kg}$ a výškou 185,10 \pm 7,44 cm. Testovaní hráči hráli v sezoně 2015/2016 nejvyšší a druhou nejvyšší republikovou soutěž a mají za sebou minimálně osm let basketbalové praxe. Během sezony absolvovali čtyři týmové tréninky, jeden kondiční trénink a jeden individuální trénink týdně. Před samotným měřením byli hráči seznámeni s průběhem a cílem měření, následně podepsali informovaný souhlas s účastí na měření.

\section{Metody sběru dat}

Pro potřeby měření byl použit specifický únavový protokol ( $\mathrm{SBFP}_{28}$; Hulka et al., 2017), který byl konstruován tak, aby kopíroval zatížení hráčů během 28 minut utkání basketbalu, což je průměrná hrací doba osmi nejnasazovanějších hráčů v družstvech nejvyšší české basketbalové soutěže. Každý hráč absolvuje čtyři měřená období, kdy po prvním a třetím období je 2 min přestávka a po druhém období pak 15 minut. Každé období se skládá ze 17 kol, které obsahují činnosti maximální intenzitou (běh s rychlostí nad $5,01 \mathrm{~m} \cdot \mathrm{s}^{-1}$ ), submaximální intenzitou (běh rychlostí 2,99 až $5,00 \mathrm{~m} \cdot \mathrm{s}^{-1}$ ), nízkou intenzitou (chůze a běh rychlostí 1,50 až $3,00 \mathrm{~m} \cdot \mathrm{s}^{-1}$ ), stojem na místě (10 s) a výskoky. První část prováděná maximální intenzitou byla měřena fotobuňkami s přesností na setiny sekundy (Alge Comet 1462, Rakousko).

Všichni probandi byli měřeni během přátelského utkání, kdy byly týmy tvořeny osmi hráči a byli střídáni tak, aby každý odehrál přibližně sedm minut v každém období. 


\section{Popis měrení}

Dva týdny před prvním měřením probandi absolvovali terénní test do vita maxima „Yo-Yo intermittent level 1 recovery test" (Bangsbo, Iaia \& Krustrup, 2008) pro určení maximální srdeční frekvence $\left(\mathrm{SF}_{\max }\right) \mathrm{v}$ hale $\mathrm{v}$ rámci samostatně vyhrazené tréninkové jednotky. Tato tréninková jednotka následovala po dvou dnech odpočinku.

Pro zjištění vnitřní odezvy organismu na zatížení během přátelského utkání a $\mathrm{SBFP}_{28}$ byl monitorován průběh srdeční frekvence (SF) pomocí systému TEAM Polar²Pro (Polar Electro, Kempele, Finland). Získaná data byla přepočítána na procenta $\mathrm{SF}_{\max }$ (Ben Abdelkrim et al., 2007; McInnes et al., 1995) v šesti zónách: $<75,00 \% \mathrm{SF}_{\max }, 75,01 \% \leq \mathrm{SF} \leq 80,00 \% \mathrm{SF}_{\max }, 80,01 \% \leq \mathrm{SF} \leq 85,00 \%$ $\mathrm{SF}_{\max }, 85,01 \% \leq \mathrm{SF} \leq 90,00 \% \mathrm{SF}_{\max }, 90,01 \% \leq \mathrm{SF} \leq 95,00 \% \mathrm{SF}_{\max }, \geq 95,01 \% \mathrm{SF}_{\max }$.

Dále byla probandům zjištována koncentrace krevního laktátu z kapilární krve odebírané z bříška prstu a to před a ihned po skončení přátelského utkání a $\mathrm{SBFP}_{28}$ pomocí Lactate Scout+ (SensLab GmbH; Germany), přičemž procedura odběrů krve se řídila doporučeními výrobce diagnostické sady Lactate Scout+. Ještě před odběrem laktátu probandi skórovali na 15 bodové Borgově škále (Borg, 1998) stupeň subjektivně vnímaného zatížení.

\section{Statistické vyhodnocení dat}

Pro statistickou analýzu dat byl využit programu SPSS (verze 17.0; SPSS Inc., Chicago, IL). Pro zjištění míry závislosti mezi sledovanými proměnnými byl použit Pearsonův korelační koeficient. Pro ověření homogenity dat byl použit Leveneův test a pro hodnocení normality pak Lillieforse test. Pro posouzení velikosti rozdílů mezi hodnotami před a po sledované aktivitě jsme použili jednofaktorovou analýzu rozptylu (ANOVA). Výsledky byly počítány na hladině významnosti $p<0,05$.

\section{Výsledky}

\section{Vnitřní odezva organismu na zatížení}

Během přátelského utkání byla zjištěna průměrná SF na úrovni $174,47 \pm 8,65$ tepů $\cdot \min ^{-1}$, což odpovídá $85,61 \pm 4,83 \% \mathrm{SF}_{\max }$, přičemž individuální hodnoty SF hráčů se nacházely v rozmezí od 82,25\% do 93,64\% $\mathrm{SF}_{\max }$. Během prvního hracího období byla hodnota průměrná SF na úrovni $171,01 \pm 4,52$ tepů $\cdot \min ^{-1}$, ve druhém období 172,03 $\pm 4,71$ tepů $\cdot \min ^{-1}$, ve třetím $171,21 \pm 5,13$ tepů $\cdot \min ^{-1}$ a ve čtvrtém pak $173,53 \pm 4,97$ tepů $\cdot \min ^{-1}$. Během testu $\mathrm{SBFP}_{28}$ byla průměrná hodnota $\mathrm{SF} 175,02 \pm 7,19$ tepů $\cdot \min ^{-1}$, tedy $87,11 \pm 5,21 \% \mathrm{SF}_{\max }$, v rozmezí od 81,79 \% do $92,38 \% \mathrm{SF}_{\max }$. Mezi průměrnou hodnotou $\mathrm{SF}$ zjištěnou v utkání a průměrnou SF během testu $\mathrm{SBFP}_{28}$ byl zjištěn významný středně silný vztah $(\mathrm{r}=0,554, \mathrm{p}=0,007)$.

Korelační analýzou byl prokázán negativní vztah mezi dobou strávenou v zóně $75-80 \% \mathrm{SF}_{\max }$ a hladinou laktátu po utkání ( $\mathrm{r}=-0,52 ; \mathrm{p}=0,011)$, podobně tomu bylo v případě $\mathrm{SBFP}_{28}(\mathrm{r}=-0,48$; $\mathrm{p}=0,013)$. Naopak pozitivně korelovala doba zatížení při intenzitě 90-95\% $\mathrm{SF}_{\max } \mathrm{s}$ koncentrací krevního laktátu v utkání $(\mathrm{r}=0,51 ; \mathrm{p}=0,041)$ stejně tak jako při plnění $\operatorname{SBFP}_{28}(\mathrm{r}=0,41 ; \mathrm{p}=0,048)$.

\section{Hladina laktátu a Subjektivní vnímání zátěže}

Průměrná hladina laktátu hráčů před $\mathrm{SBFP}_{28}$ byla $1,78 \pm 0,47 \mathrm{mmol} \cdot \mathrm{L}^{-1}$ a $4,01 \pm 0,52 \mathrm{mmol} \cdot \mathrm{L}^{-1}$ po jeho absolvování, tedy rozdíl v hladině laktátu (Ladiff) byl 2,12 $\pm 0,49 \mathrm{mmol} \cdot \mathrm{L}^{-1}(\mathrm{~F}=293,21$; $\mathrm{p}=0,001)$. Průměrná hladina laktátu hráčů před přátelským utkáním $1,99 \pm 0,33 \mathrm{mmol} \cdot \mathrm{L}^{-1} \mathrm{a}$ $5,25 \pm 0,78 \mathrm{mmol} \cdot \mathrm{L}^{-1}$ po něm $(\mathrm{F}=61,52 ; \mathrm{p}=0,001)$, průměrná Ladiff činila $2,84 \pm 0,67 \mathrm{mmol} \cdot \mathrm{L}^{-1}$.

Aplikovaná Borgova škála po $\mathrm{SBFP}_{28}$ byla $13,72 \pm 1,64$ a $15,20 \pm 1,21$ po přátelském utkání. Těsnost vztahu mezi hodnotami Ladiff během utkání a $\mathrm{SBFP}_{28}$ byla $\mathrm{r}=0,269(\mathrm{p}=0,183)$ a $\mathrm{r}=, 249$ $(\mathrm{p}=0,210)$ pro pozátěžové hodnoty hladiny laktátu a $\mathrm{r}=0,59(\mathrm{p}=0,01)$ pro subjektivně vnímané zatížení. Při hodnocení vztahu mezi hodnotami hladiny laktátu a průměrné SF jsme zjistili jen malou míru závislosti a to jak v utkání $(\mathrm{r}=0,29 ; \mathrm{p}=0,148)$, tak u $\mathrm{SBFP}_{28}(\mathrm{r}=0,26 ; \mathrm{p}=0,390)$. Při posouzení závislosti vztahu mezi průměrnou SF v jednotlivých obdobích utkání a pozátěžovou hladinou laktátu jsme zjistili nízkou úroveň závislosti v prvním $(\mathrm{r}=0,31 ; \mathrm{p}=0,090)$ a druhém období $(\mathrm{r}=0,35$; $\mathrm{p}=0,041)$ a naopak středně silnou u třetího $(\mathrm{r}=0,43, \mathrm{p}=0,021)$ a čtvrtého $(\mathrm{r}=0,68 ; \mathrm{p}=0,001)$ období. 
Diskuse

Cílem studie bylo ověření validity měření specifickým basketbalovým únavovým protokolem $\mathrm{SBFP}_{28}$ pomocí porovnání objektivních a subjektivních ukazatelů vnitřní odezvy organismu na zatížení během $\mathrm{SBFP}_{28}$ a utkáním.

Protokol $\mathrm{SBFP}_{28}$ vznikl simulací vnějšího zatížení hráčů, především pak počtem činností prováděných maximální intenzitou, změn směru, zrychlení a zpomalení, výskoků a překonané vzdálenosti (Hůlka et al., 2017).

Průměrná SF hráčů během utkání se pohybuje v oblasti vysoké intenzity, i přesto že většinu času hráči tráví činností střední a nízké intenzity (Narazaki, Berg, Stergiou, \& Chen, 2009). Naše výsledky tento trend potvrzují. Stejně tak jako koncentrace laktátu v krvi po přátelském utkání hráčů druhé divize americké univerzitní soutěže, kdy Narazaki (2007) zjistili 4,2 $\pm 1,9 \mathrm{mmol} \cdot \mathrm{L}^{-1}$, Ben Abdelkrim et al. (2010) 5,75 $\pm 1,25 \mathrm{mmol} \cdot \mathrm{L}^{-1}$ a Mathews a Delextrat (2009) změřili $5,2 \pm 2,7 \mathrm{mmol} \cdot \mathrm{L}^{-1}$. Narazaki et al. (2007) dále zjistili podobnou úroveň subjektivně vnímaného zatížení a to $13,7 \pm 1,0$. Mưžeme říci, že metabolické odpovědi hráčů během přátelského utkání v basketbale $\left(5,25 \pm 0,78 \mathrm{mmol} \cdot \mathrm{L}^{-1}\right)$ jsou podobné těm, které byly zjištěny již dříve.

Při porovnání průměrné srdeční frekvence během přátelského utkání i testu $\mathrm{SBFP}_{28}$ byl zjištěn rozdíl přibližně dvou procent $\mathrm{s}$ korelací $\mathrm{r}=0,554$, stejně tak jako u subjektivního vnímámí zatížení. Naopak pozátěžová hladina laktátu v krvi s ostatními sledovanými parametry koreluje jen málo. Podle Duthie, Pyne a Hooper (2003) se to stává v momentě, kdy porovnávané testy neobsahují neortodoxní pohybovou aktivitu, tedy nedostatečnou biomechanickou specifičností testu, což ale není případ $\mathrm{SBFP}_{28}$, který ukazuje na vysokou validitu (Hůlka et al., 2017). Dalším důvodem by mohla být nižšśi metabolická specifičnost, kdy v utkání je zatížení intermitentního charakteru díky nepředvídatelnosti průběhu hry (Wadley \& Rossignol, 1998), kdežto $\mathrm{SBFP}_{28}$ vychází z průměrných hodnot vnějšího zatížení v utkání a má charakter intervalový, tedy pravidelný odpočinek versus možné kumulované úseky prováděné maximální intenzitou. Díky tomu pravděpodobně nedochází v první polovině $\mathrm{SBFP}_{28}$ ke hromadění laktátu v krvi, ale organismus je schopen jej v intervalech odpočinku odbourat. Vyvstává tak otázka, zda vůbec lze konstruovat validní test, který by simuloval variabilní podmínky utkání.

Díky těsnosti vztahu mezi průměrnou srdeční frekvencí v jednotlivých obdobích a pozátěžovou hladinou laktátu po utkání se ukazuje, že tento hladina krevního laktátu má velmi dynamický průběh (Bangsbo, Norregaard \& Thorso, 1991), proto hladina laktátu naměřená po ukončení utkání zř̌ejmě reflektuje zatížení pouze konce utkání. Tento fakt může poukazovat na nízkou validitu hodnocení indikátoru pozátěžové hladiny laktátu jako ukazatele vnitřní odezvy organismu na zatížení v celém utkání (Coutts, Reaburn, \& Abt, 2003; Gamble, 2007).

\section{Závěry}

Porovnáním výsledků monitorování srdeční frekvence během přátelského utkání a testu $\mathrm{SBFP}_{28}$ jsme zjistili středně silnou statisticky významnou korelaci. Podobně tomu bylo i u sledování pozátěžové hladiny laktátu v krvi u obou sledovaných aktivit. Nicméně těsnost vztahu mezi hodnotami Ladiff během utkání a $\mathrm{SBFP}_{28}$ byly hodnoty korelace velmi nízké, tedy metabolická odezva organismu na zatížení v utkání a $\mathrm{SBFP}_{28}$ je odlišná. Tento fakt je přisuzován rozdílem mezi zatížením intervalové a intermitentní povahy.

\section{Literatura}

Apostolidis, N., Nassis, G. P., Bolatoglou, T., \& Geladas, N. D. (2004). Physiological and technical characteristics of elite young basketball players. Journal of Sports Medicine and Physical Fitness, $44(2), 157-163$.

Bangsbo, J. L., Norregaard, L., \& Thorso, F. (1991). Activity profile of competition soccer. Canadian Journal of Sports Sciences, 16, 110-116.

Bangsbo, J., Iaia, F. M., \& Krustrup, P. (2008). The Yo-Yo intermittent recovery test - A useful tool for evaluation of physical performance in intermittent sports. Sports Medicine, 38(1), 37-51.

Ben Abdelkrim, N. B., El Fazaa, S., \& El Ati, J. (2007). Time-motion analysis and physiological data of elite under-19-year-old basketball players during competition. British Journal of Sports Medicine, 41(2), 69-75. 
Ben Abdelkrim, N., Castagna, C., Jabri, I., Battikh, T., El Fazaa, S., \& El Ati, J. (2010). Activity Profile and Physiological Requirements of Junior Elite Basketball Players in Relation to AerobicAnaerobic Fitness. Journal of Strength and Conditioning Research, 24(9), 2330-2342.

Bishop, D. C., \& Wright, C. (2006). A time-motion analysis of professional basketball to determine the relationship between three activity profiles: high, medium and low intensity and the length of the time spent on court. International Journal of Performance Analysis in Sport, 6(1), 130-139.

Boddington, M. K., Lambert, M. I., Gibson, A. S. C., \& Noakes, T. D. (2001). Reliability of a 5-m multiple shuttle test. J Sports Sci, 19(3), 223-228.

Borg G. (1998). Borg's perceived exertion and pain scales. Champaign, IL: Human Kinetics.

Capranica, L., Tessitore, L., \& Guidetti, L. (2001). Heart rate and match analysis in pre-pubescent soccer players. Journal of Sports Sciences, 19(6), 379-384.

Coutts, A., Reaburn, P., \& Abt, G. (2003). Heart rate, blood lactate concentration and estimated energy expenditure in a semi-professional rugby league team during a match: a case study. Journal of Sports Sciences, 21, 97-103.

Duthie, G., Pyne, D., \& Hooper, S. (2003). Applied physiology and game analysis of rugby union. Sports Medicine (Auckland, N.Z.), 33(13), 973-991.

Erčulj, F., Dežman, B., Vučkovič, G., Perš, J., Perš, M., \& Kristan, M. (2008). An analysis of basketball players' movoments in the slovenian basketball league play-offs using the SAGIT tracking system. Facta Universitatis. Series: Physical Education and Sport, 6(1), 75-84.

Gamble, P. (2006). Implications and applications of training specificity for coaches and athletes. Strength and Conditioning Journal, 28(3), 54-58.

Gamble, P. (2007). Challenges and game-related solutions to metabolic conditioning for team sports. Strength and Conditioning Journal, 29(4), 60-65.

Hůlka, K., Bělka, J., Cuberek, R., \& Schneider, O. (2014). Reliability of specific on-ice repeated-sprint ability test for ice-hockey players. Acta Gymnica, 44(2), 69-75.

Hůlka, K., Cuberek, R., \& Bělka, J. (2013). Heart rate and time-motion analyses in top junior players during basketball matches. Acta Universitatis Palackianae Olomucensis, Gymnica, 43(3), 27-35.

Hůlka, K., Lehnert, M., \& Bělka, J. (2017). Reliability and validity of basketball-specific fatigue protocl simulating match load. Acta Gymnica, 47(2), 92-98.

Klusemann, M. J., Pyne, D. B., Hopkins, W. G., \& Drinkwater, E. J. (2013). Activity Profiles and Demands of Seasonal and Tournament Basketball Competition. International Journal of Sports Physiology and Performance, 8(6), 623-629.

Krustrup, P., Mohr, M., \& Bangsbo, J. (2002). Activity profile and physiological demands of topclass soccer assistant refereeing in relation to training status. Journal of Sports Sciences, 20(11), 861-871.

Matthew, D., \& Delextrat, A. (2009). Heart rate, blood lactate concentration, and time-motion analysis of female basketball players during competition. Journal of Sport Sciences, 27(8), 813-822.

McInnes, S. E., Carlson, J. S., Jones, C. J., \& McKenna, M. J. (1995). The physiological load imposed on basketball players during competition. Journal of Sports Sciences, 13(5), 387-397.

McKeag, D. B. (2003). Handbook of sports medicine and science, basketball. Wiley: Blackwell publishing.

Montgomery, P. G., Pyne, D. B., \& Minahan, C. L. (2010). The physical and physiological demandsof basketball training and competition. International Journal of Sports Physiology and Performance, 5, 75-86.

Narazaki, K., Berg, K., Stergiou, N., \& Chen, B. (2009). Physiological demands of competitive baksteball. Scandinavian Journal of Medicine \& Science in Sports, 19(3), 425-432.

National Coaching Foundation (1995). The role of fitness testing $\&$ selecting and using fitness tests. Leeds: NCF.

Scanlan, A. T., Dascombe, B. J., Reaburn P., \& Dalbo, V. J. (2012). The physiological and activity demands experienced by Australian female basketball players during competition. Journal of Science and Medicine in Sport, 15(4), 341-347.

Taylor, J. (2004). A tactical metabolic training model for collegiate basketball. Strength and Conditioning Journal, 26(5), 22-29. 
Wadley, G., \& Le Rossignol, P. (1998). The relationship between repeated sprint ability and the aerobic and anaerobic energy system. Journal of Science and Medicine in Sport, 1(2), 100-110.

Mgr. Karel Hůlka, Ph.D.

KAS FTK UP v Olomouci

Hynaisova 9

PSČ: 77900 Olomouc, CZ

karel.hulka@upol.cz 